\title{
Battle heats up over control of workers' health
}

The US Occupational Safety and Health Administration will soon face one of the severest political challenges of its tenyear existence. In the second of three articles on the current anti-regulatory mood in Washington David Dickson reports on pressures on the agency and their implications for environmental research

Within the next few weeks a Senate Committee will begin discussing two bills either of which could, if implemented by Congress, significantly restrict the activities of the Occupational Safety and Health Administration (OSHA).One proposes a partial exemption for a large number of companies from the provisions of the act which set up the agency in 1970; the second is a stronger bill which would mean total exemption for small businesses removing the agency's jurisdication over more than four million workers.

Attempts to limit the activities of OSHA - perhaps the federal agency least loved by the US business community - have frequently been launched in Congress, but have seldom gathered much momentum. This year, however, the situation of different. Defenders of the agency have less support than previously; while critics, buoyed by their success in securing an amendment to OSHA's appropriations bill which effectively bars the agency from routine safety checks on 1.5 million establishments, are confident that at least one of the new bills may reach the statue book.

Disenchantment with OSHA has been directly fuelled by the anti-regulatory mood that is increasingly dominating both the Congress and the administration. Much of this has its roots in the economic argument that excessive regulation has been an important contributor to inflation, in particular reducing the rate of technological innovation and thus slowing productivity growth.

But behind this there is a political argument over who should have prime responsibility for protecting the health of the worker. Whether it should be the federal government, in its role of social regulator; or whether the responsibility should be passed partially back to private industry, operating under broad government guidelines, but responding primarily to economic incentives and the dictates of the market-place.

Support for the latter view is growing in strength. But to the extent that such sentiments have already been relected in various Congressional actions, they have

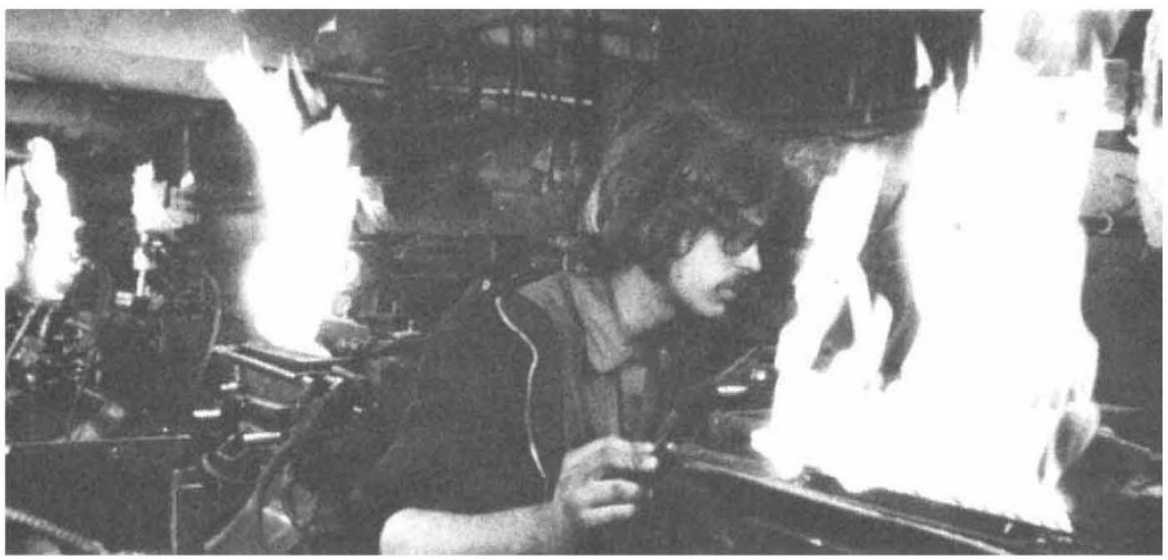

been strongly condemned by the trade unions. In a report on recent and current legislative moves, for example, the United Steelworkers of America says that 1978 and 1979 were "dismal" years in Congress for workers safety and health.

"The errant pot shots that had been fired at OSHA every year since its enactment have now improved in their accuracy and their potency, and real erosion is beginning to take place", the union says.

The seeds of the present conflict between supporters and critics of OSHA were sown in the 1970 act establishing the agency. This requires OSHA to work towards achieving a "safe and healthful" environment for every US worker - but gave little specific indication as to which criteria should be used to make this assessment.

Initially OSHA came under steady fire for appearing to concentrate on "nitpicking" issues, such as the height of fire extinguishers above the floor, and ignoring many of the more important health and safety standards.

Its image of ineffectiveness and pettyminedness has been successfully revamped under OSHA's present head, Dr Eula Bingham. Appointment by President Carter in 1977, Dr Bingham has shifted the main emphasis from safety to health - a move reflected in the fact that OSHA has produced more health standards in the last two years than it did in the previous six.

Agency of ficials point to one of its major successes as being an increased public awareness of the importance of occupational health as a sccial issue. But they acknowledge the paradox that this has occurred precisely at a time when there are growing demands for the government to reduce its regulatory activities; and that this puts OSHA and its supporters in a vulnerable situation.

Evidence of this shift in public mood is provided by the speed with which even "liberal" politicians are now jumping on the regulatory band-wagon. The more restrictive of the two proposed Senate bills, for example, has been submitted by Senator Franch Church of Idaho, considered a liberal in US politics, but facing a tough challenge from the right in his re-election battle next year.

"Having someone like Church, who we do not consider an enemy, against you makes things a lot harder to deal with," says George Taylor of the AFL-CIO (American Federation of Labour Council of Industrial Organisations), who foresees a need for the unions to "fight like hell" to protect some of the gains made in recent years.

It has become politically acceptable to challenge the activities of regulatory agencies. Speaking at a meeting of the American Chemical Society in Washington two weeks ago, for example, Dr P M Nortling, director of health and safety for the Du Pont Chemical company, said that although the number of citations for illegal practices issued by OSHA had diminished over the past two years, the proportion challenged by industry had almost doubled, from seven to $12 \%$ over this period.

\section{Corporate attitudes}

"There has been an important change in corporate attitudes. In the past, corporations were unwilling to appear obstructive on health and safety issues. That reluctance is now giving way, and we are now seeing the chemical industry taking a very active role in challenging regulatory proposals, particularly those which we feel impose economic burdens incommensurate with the expected benefits," Dr Norling said.

Ironically many of the current controversies result from a surfeit of laboratory data about the physiological effects of particular substances - at least when compared to the relative lack of epidemiological data on human health implications of the type which can be used as a solid basis for regulation.

A typical case in point it OSHA's proposal to implement "generic", carcinogen controls and standards. Under this proposal, first put forward two years ago and expected to be published in its final form next month, the agency will classify as a carcinogen any substance known to produce tumours in any single species of laboratery animal - and will demand that Above: working in a steel foundry 
occupational exposure to this substance should be reduced as low as technologically feasible.

OSHA scientists argue that, given the many uncertainties that surround the mechanisms of carcinogenisis, workers should be given the benefit of the doubt. And this means protecting them against any substance bearing the least suspicion of carcinogenic properties.

The chemical industry, on the other hand, has attacked this approach as being both unnecessarily expensive - it quotes a cost for implementing the proposals as between $\$ 8$ and $\$ 88$ million - and as inherently "unscientific". The industry argues that more substantial data is required before taking such drastic action; this might, for example, include classfying carcinogens in terms of relative potency.

The industry has formed a lobbying group, the American Industrial Health Council, specifically to challenge OSHA's proposals - referred to last week as an "administrative short-cut" by AIHC executive director Ronald A Lang.

One AIHC proposal meeting with more sympathy in the administration, however, is that there should be a clearer distinction between the scientific and the political decisions made in the regulatory process. The AIHC has proposed that the National Academy of Sciences appoint a panel of "the best scientists the government can tap" to assess whether a particular substance is or is not a potential human hazard, and if so to what degree. The appropriate control mechanisms would them be agreed by a separate body.

A similar, although not identical, twostage process for dealing with occupational hazards is already being developed within the administration, using the Department of Health, Education and Welfare's National Toxicology Programme to centralise the scientific assessment of potential hazards; and further developments along these lines are expected to be contained in a report from the President's newly apointed Regulatory Council, due in a few weeks time.

Even though such centralisation may have advantages in terms of efficiency, however, not everyone is totally convinced of its merits, some fearing that it might put a strait-jacket on the flexibility made possible by a plurality of programmes. "If there is an indication that these joint programmes are used to explore certain questions and to neglect others, that will be a real problem," says Dr Robbins of the National Institute of Occupational Safety and Health.

But the pressures to change the whole shape of Washington's regulatory apparatus continue to build, Until a few months ago, the dominant demand was that this apparatus should be "rationalised" in the interests of cost effectiveness. More recently, there has been what Dr Frank Press, director of the Office of Science and Technology Policy, has referred to as the emergence of a "new philosophy" emphasising economic incentives rather than regulatory clout.

Speaking at the ACS meeting two weeks ago, Dr Press suggested that industry should be given more flexibility in deciding how to achieve overall regulatory goals established by society. This could be done, for example, by applying the "bubble concept" used for air pollution control requiring merely that a plant's total effluence release complies with federal standards - to health and safety.

"One of the important things to recognise regarding this approach to regulation is that it provides new incentive to industry to innovate. It takes some of the repressiveness and uncertainty out of regulation, and relies more on marketforces to achieve the desired goals in environmental quality, health and safety."

New legislation along these lines may well emerge in the next few weeks, when President Carter announces the conclusions that he has reached following a year-long review by the Department of Commerce of the effects of government policy on industrial innovation; the forty recommendations passed to the White House for presidential decisions include a number on regulatory reform, including for example a proposal to shift from design to performance criteria as the basis for regulation.

A number of observers in Washington feel that, with an election year approaching, it would be difficult for the President to support any major roll-back in occupational safety legislation - if only because trade union support is probably more important than that of environmentalists who have complained of the impact of proposed energy legislation.

But within the administration there is considerable dispute over whether the incentives approach is the right one to take. OSHA, for example, has been strongly opposed to demands that health and safety

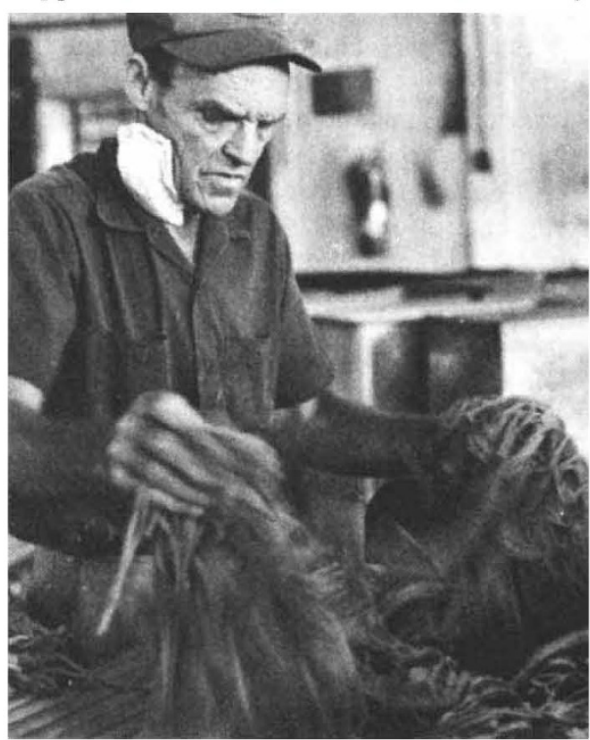

US textile worker: stringent limits to cotton dust exposure have been one of OSHA's recent successes regulation should be justified on economic grounds, arguing in particular that there is no way that a worker's health can be adequately quantified - and certainly not by putting a market value on it.

Indeed almost all sides in the dispute on an appropriate policy now seem to accept that the vagaries of cost-benefit analysis are such as to make it an inadequate basis for regulatory decision-making - and that no statistic can really be trusted to give a full reflection of either the costs of regulation or its benefits.

As far as Congress is concerned, the response has been explicitly political. "Ultimately out belief is that the protection of the work-force is the responsibility of the employer, working with the employee, not of the OSHA policeman holding a club" says Mark de Bernardo of the Chamber of Commerce, a Washington-based group representing private industry interests which is providing active support to legislative attempts to change OSHA's mandate.

\section{Trade unions}

Trade unions and their supporters, however, see things differently. Although critical of the relative lack of impact which OSHA has had in the past, they credit it with many important gains, for example some of its recent programmes in worker education. And they are convinced that the health of workers can be better achieved through an effective regulatory agency rather than through the collective bargaining process.

"Protecting the gains made by OSHA is going to require vigilance and hard work," says George Coling of the Urban Environment Congerence, a lobby group which has been engaged in developing a coalition of labour, environmentalist and minority groups on occupational health issues. "It is not a battle for the agency, but it is a battle for health - and the agency is the tool that we need."

Ironically, the one aspect of federal health and safety efforts which has so far been relatively immune from Congressional attack has been the research budget. The budget for NIOSH, for example, is scheduled to increase by 25 per cent for the fiscal year 1980, reflecting the administration's commitment, articulated through the science adviser's office, to improve the "science base" of its various spheres of activity.

Yet even this may have its price. "It is possible that Congress may want to put more money into research rather than into adequate reinforcement. We obviously welcome the extra funds; but in the longrun such a shift in emphasis would not be a good thing; it might mean that we could produce more results, but it would give the administration less ability to put these results into practice," says Dr Robbins of NIOSH.

Next week: problems with non-proliferation 